Military Technical

College

Kobry El-Kobba

Cairo, Egypt

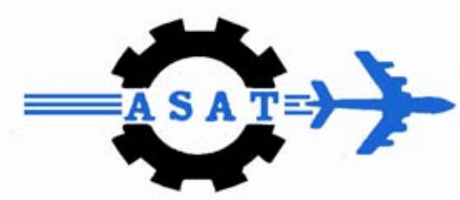

12-th International Conference on

Aerospace Sciences \& Aviation Technology

\title{
DEVELOPMENT OF A COMPUTER BASED LEARNING TOOL FOR UNDERSTANDING AIRCRAFT STRUCTURES
}

\author{
Farrukh Mazhar, Abdul Munem $^{* *}$ Khan, and $\operatorname{Irfan}^{* \star *}$ Aziz
}

\begin{abstract}
In today's engineering design, extensive mathematical calculations / computational analysis are done, which requires powerful engineering software to facilitate and reduce the mathematical workload. This paper pertains to the development of a computer based learning software, named "STATOL ${ }^{\circledR}$ ", for understanding aircraft structures. The software is developed to analyse complex structures used in aircraft constructions, with an aim to facilitate understanding of such problems in a class and enable the user to perform parametric study to appreciate the effect of varying different input on the resultants. The computer code is written in Microsoft Visual Basic $6^{\circledR}$.
\end{abstract}

\section{KEYWORDS}

Structures, Aircraft Structures, Shear Flow distribution, Software, Computer-based Learning Tool, Theory of Beams,

\section{NOMENCLATURE}
A Area
C Constant
E Modulus of Elasticity
I Moment of Inertia
$\boldsymbol{M} \quad$ Moment
$\boldsymbol{P} \quad$ Force
$\boldsymbol{Q} \quad$ Shear flow
S Width of plate
$\boldsymbol{t} \quad$ Thickness of plate
$\boldsymbol{T}$ Temperature
$\boldsymbol{x} \quad$ Length of plate
$\boldsymbol{X} \quad$ Displacement in $\mathrm{X}$ axis

*Dept of Industrial Engg, College of Aeronautical Engg, National University of Science and Technology, Rawalpindi, Pakistan.

${ }^{\star *}$ Dept of Aerospace Engg, College of Aeronautical Engineering, National University of Science and Technology, Rawalpindi, Pakistan.

***Dept of Mech Engg, University of Engineering and Technology, Peshawar, Pakistan. 


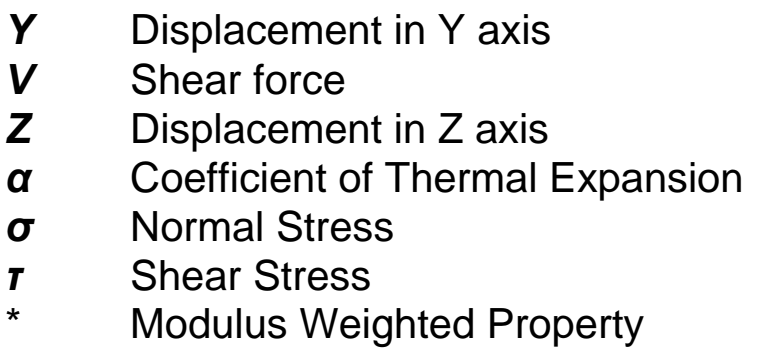

\section{INTRODUCTION}

Present day's engineering design / analysis requires extensive mathematical calculations, which asks for a mammoth requirement of engineering software to facilitate and reduce the computational workload. At advanced level undergraduate courses of Aerospace structures the requirement of simple and easily learnable software was, therefore, felt for imparting better understanding of the course contents and to undertake parametric study to appreciate the effect and behaviour of aircraft structures under different loading conditions. To meet these requirements, authors have developed a software named STATOL ${ }^{\circledR}$ (Structural Tool) that can be described as a computer based learning software.

STATOL ${ }^{\circledR}$ is developed in Visual Basic ${ }^{\odot}$. User-friendly environment and enhanced Graphical user interface (GUI) of Visual Basic ${ }^{\odot}$ language are key factors behind the selection of the programming language.

\section{SCOPE}

The preliminary development of the software included the analysis of longitudinal stresses, compression forces, bending moments, and thermal loading affects on typical aircraft structures. Later on, Shear Flow calculations, Bucking Analysis and Principal Stresses calculations were also made part of the software as an additional work. The latest development of the software includes the shear flow distribution analysis.

\section{THEORY OF BEAMS AND SHEAR FLOW DISTRIBUTION IN STRUCTURES}

STATOL ${ }^{\circledR}$ is developed for understanding the application of the theory / analysis of bending / extensions of the beams / structures and shear flow distribution in aircraft structures. STATOL ${ }^{\circledR}$ is based upon concepts given in references [1] and [2]. A brief introduction to the concepts is given in the subsequent paragraphs.

\section{Stresses and Stress Resultants on a Beam Cross Section Due to Extension and Bending}

The theory is explained with the help of figure 1 . Here, the force and moment resultants of the stress are acting upon the cross sections of the beam. The stresses on the differential area $d A$ at point $B$ with co-ordinates $(x, y, z)$ are $\sigma_{x x}, \sigma_{x y}$ and $\sigma_{x z}$. The resultant of these stresses on the cross section consists of a force and $a$ 
moment, whose components are axial component $P$, and shear components $V_{y}$ and $V_{z}$, and the moment components are torsional moment $M_{t}$, and bending moments $M_{y}$, and $M_{z}$, which are about axes their parallel axes. The outcome of all calculation comes out to be following equation (the detailed equations development may found out as given in reference [1]):-

$$
\sigma_{x x}=\frac{E}{E_{1}}\left[\frac{P^{*}}{A^{*}}-\frac{M_{z} * I_{y y} *-M_{y} * I_{y z} *}{I_{y y} * I_{z z} *-\left(I_{y z}\right)^{2}} y-\frac{M_{y} * I_{z z} *-M_{z} * I_{y z} *}{I_{y y} * I_{z z} *-\left(I_{y z} *\right)^{2}} Z\right]
$$

This relation is used to calculate resultant stresses form external loads $P$ (axial component) and bending moments $M_{y}$ and $M_{z}$.

The coordinates of modulus-weighted centroid are given as:-

$$
\begin{aligned}
& \bar{y}_{o} *=\frac{1}{A *} \sum_{i=1}^{n} \bar{y}_{i 0} A_{i} * \\
& \bar{z}_{o}^{*}=\frac{1}{A *} \sum_{i=1}^{n} \bar{z}_{i o} A_{i} *
\end{aligned}
$$

Also

$$
\begin{aligned}
I^{*}{ }_{y_{o} y_{o}} & =\sum_{i=1}^{n} \frac{E_{i}}{E_{1}}\left(I_{y y_{o_{i}}}+\bar{z}_{i}{ }^{2} A_{i}\right) \\
I^{*}{ }_{z_{o} z_{o}} & =\sum_{i=1}^{n} \frac{E_{i}}{E_{1}}\left(I_{z z_{o_{i}}}+{\overline{y_{i}}}^{2} A_{i}\right) \\
I^{*}{ }_{y_{o} z_{o}} & =\sum_{i=1}^{n} \frac{E_{i}}{E_{1}}\left(I_{y z_{o_{i}}}+\bar{z}_{i} \overline{y_{i}} A_{i}\right)
\end{aligned}
$$

And

$$
\begin{gathered}
I_{y y} *=I_{y_{o} y_{o}} *-\left(\bar{z}_{o} *\right)^{2} A * \\
I_{z z} *=I_{z_{o} z_{o}} *-\left(\bar{y}_{o} *\right)^{2} A * \\
\quad I_{y z} *=I_{y_{o} z_{o}} *-\bar{z}_{o} * \bar{y}_{o} * A
\end{gathered}
$$

\section{Shear Flow Due to Shear in Thin Walled Open Section Slender Beams}

This section deals with the calculation of resultant form external shear components of loads and bending moments. A differential length of a homogenous beam of arbitrary thin walled cross section is shown in figure 2. It is assumed that a beam is subjected to shear force $V$ and a temperature change $T(x, y, z)$. The transverse ribs or frames (rigid in $y$ and $z$ directions but flexible in $x$ direction) maintain the cross sectional shape but allow free warping out of the plane of the cross section. 
Figure 3 shows the free body diagram of differential length of a typical wall of a structure shown in figure 2. The coordinate $s$ which locates this element is measured along the midline of the wall from an arbitrary point $O$ in the wall.

Summing the forces in the $x$ direction, dividing by $d x d s$, taking the limit as $d s$ approaches zero. The outcome of all calculation comes out to be following equation (the detailed equations derivations are given in reference [1]):

$$
q=q_{o}+\frac{A_{s}^{*}}{A^{*}} p_{x \tau}+C_{2} Q^{*}{ }_{z}+C_{3} Q^{*}{ }_{y}+\int_{0}^{s} E(\alpha T)^{\prime} t d s
$$

Where,

$$
q=\sigma_{x s} t
$$

The constants $\mathrm{C}_{2}{ }_{2}$ and $\mathrm{C}_{3}$ are calculated by the following relations:

$$
\begin{aligned}
& C_{2}{ }^{\prime}=\frac{V_{y}^{*} I_{y y}^{*}-V_{z}^{*} I_{y z}^{*}}{I_{y y}^{*} I_{z z}^{*}-\left(I_{y z}^{*}\right)^{2}} \\
& C_{3}{ }^{\prime}=\frac{V_{z}^{*} I_{z z}^{*}-V_{y}^{*} I_{y z}^{*}}{I_{y y}^{*} I_{z z}^{*}-\left(I_{y z}^{*}\right)^{2}}
\end{aligned}
$$

\section{VERIFICATION OF RESULTS}

\section{Stresses Resultants on a Beam Cross Section}

Assume the case of a simplified representation of a beam construction used in the aerodynamic surfaces of flight vehicles as shown in figure 4 . The beam is acted upon by the thermal effects (as shown in figure 4) and a bending moment of $10^{6} \mathrm{in}-\mathrm{lb}$. It is assumed that the compression skin remains unbuckled and the structure is idealizing into longitudinals that carry only axial stresses and webs that sustain only shear stresses.

The coefficient of thermal expansion is $1.26 E-5{ }^{\circ} \mathrm{F}$. The initial temperature of the structure is $70{ }^{\circ} \mathrm{F}$. The external load is zero. The moment about $\mathrm{x}$-axis is $1 E 6 \mathrm{in}-\mathrm{lb}$. The moment about $Y$ axis is zero. The total cross sectional area $A^{*}=1.797 E+1 \mathrm{in}^{2}$. The coordinate of centroid are (20.90 in and $5.215 \mathrm{in})$.

The values of the moment of inertia about different axes are

$$
\begin{aligned}
& I_{x x}{ }^{*}=4.247 E+2 i^{4}, \\
& I_{y y}=7.063 E+3 i^{4}, \\
& I_{x y}=-4.705 E+2 i n^{4}
\end{aligned}
$$

The equivalent thermal loads are 


$$
\begin{aligned}
& P^{*}=P+P_{T}=6.943 E+5 \mathrm{lb} . \\
& M_{x}{ }^{*}=M_{x}+M_{x T}=1.445 E+6 \mathrm{in}-\mathrm{lb} \\
& M_{y}{ }^{*}=M_{y}+M_{y T}=1.146 E+5 \mathrm{in}-\mathrm{lb}
\end{aligned}
$$

The value of $\sigma_{x x} / E$ can be calculated by the following relation

$$
\sigma_{x x} / E=C_{1}+C_{2} X_{1}+C_{3} y_{1}-\alpha T
$$

The calculated values of the constants are

$$
\begin{aligned}
& C_{1}=3.863 E-3 \\
& C_{2}=-2.622 E-5 \\
& C_{3}=-3.693 E-4
\end{aligned}
$$

The detailed results are given in table 1 and table 2 . It may be highlighted that the results are verified to be accurate to almost double in accuracy as compared to manual calculations or calculations done by Excel spreadsheet; since the code is programmed using double precision (64 bits long) numerals.

\section{Shear Flow Due to Shear in Thin Walled Open Section Slender Beams}

In this case same beam construction as shown in figure 4 is analyzed for shear flow calculations. Here, the section is open with skin is cut between longitudinal 14 and 15. The beam is subjected to a vertical shear force of $2000 \mathrm{lb}$ at the shear centre and there is a longitudinal thermal gradient of $T_{i}{ }^{\prime}=-2.083 \times 10^{-3} T_{i}{ }^{\circ} \mathrm{F} /$ in where $T_{i}{ }^{\prime}$ is the axial rate of change of temperature change in the ith longitudinal and $T_{i}$ is the temperature in ith longitudinal.

The computations for $p_{x T}, V_{x T}, V_{y T}$ are given as

$$
\begin{aligned}
& P_{x T}=-1443.17 \mathrm{lb} / \mathrm{in}, \\
& V_{x T}{ }^{*}=217.56 \mathrm{lb}, \\
& V_{y T}{ }^{*}=-1073.32 \mathrm{lb}
\end{aligned}
$$

The calculated values of the constants are

$$
\begin{aligned}
& C_{2}{ }_{2}=-0.1573 \\
& C^{\prime}{ }_{3}=-1.4348
\end{aligned}
$$

The detailed results are given in table 3 and table 4 . Here again, the results are verified to be accurate to almost double in accuracy as compared to manual calculations or calculations done by Excel spreadsheet; since the code is programmed using double precision (64 bits long) numerals.

\section{STATOL ${ }^{\circledR}$ HIERARCHY}

The simplified flow diagram of the STATOL ${ }^{\circledR}$ software is shown in fig 9. A few STATOL ${ }^{\circledR}$ are shown from fig 6 to 8 


\section{Introduction}

STATOL ${ }^{\circledR}$ software consists of four major modules as:
(a) Shell Stress Analysis
(b) Shear Flow analysis
(c) Buckling Analysis
(d) Principal Forces calculation

\section{CONCLUSION}

This paper presents the development of STATOL ${ }^{\circledR}$ software. The software code is written with an aim to impart knowledge of basics of structural analysis for understanding construction used in medium advanced aircraft. Although detailed code of STATOL ${ }^{\circledR}$ was not presented in this paper, however, the software was tested for several problems and results obtained were also authenticated manually and using Microsoft Excel ${ }^{\circledR}$ spreadsheets, validating software's double-precision accuracy; since code is programmed using double precision (64 bits long) numerals.

\section{References}

[1] Rivello, Robert M., "Theory and Analysis of Flight Structure”, McGraw-Hill, 1969.

[2] Higdon, Archie, "Mechanics of Materials", John Willie \& Sons, 1985

[3] Coultas, H. W., "Theory of Structures", Pitman and Sons Ltd., 1963.

[4] Michelle Moore, "Learn Visual Basic ${ }^{\circledR}$ Today", IDG Books, 1995.

[5] Cornell, Gary, "Visual Basic ${ }^{\circledR}$ for Windows Handbook”, McGraw-Hill, 1993.

[6] Petroutsos, Evangelos, "Mastering Visual Basic ${ }^{\circledR}$ 6", Sybex Computer Books, 1998. 
Table 1. Detailed Resultant (Part :A)

\begin{tabular}{|c|c|c|c|c|c|c|c|c|c|c|c|c|c|c|}
\hline Node & $\begin{array}{l}\mathrm{Ai} \\
\mathrm{in}^{2}\end{array}$ & $\begin{array}{c}\text { Xcood } \\
x i \text { in }\end{array}$ & $\begin{array}{l}\text { Ycood } \\
\text { yi in }\end{array}$ & $\begin{array}{l}\mathrm{T} \\
{ }^{0} \mathrm{~F} \\
\end{array}$ & $E / E^{*}$ & $\begin{array}{l}A^{*} \\
i^{2}\end{array}$ & $\begin{array}{l}\text { Ax } \\
\text { in }^{3}\end{array}$ & $\begin{array}{l}\text { Ay } \\
\text { in }^{3}\end{array}$ & $\begin{array}{c}\text { Asqx } \\
\text { in }^{4}\end{array}$ & $\begin{array}{c}\text { Asqy } \\
\text { in }^{5}\end{array}$ & $\begin{array}{l}\text { Axy } \\
\text { in }^{6}\end{array}$ & $\begin{array}{l}X \\
\text { in }\end{array}$ & $\begin{array}{l}Y \\
\text { in }\end{array}$ & $\begin{array}{l}\mathrm{Tt} \\
{ }^{0} \mathrm{~F} \\
\end{array}$ \\
\hline 1 & 3 & 0 & 12 & 300 & .95 & 2.85 & 0 & 34 & 0 & 410.4 & 0 & -20.94 & 6.78 & 230 \\
\hline 2 & 0.49 & 0 & 9.47 & 275 & 0.96 & 0.47 & 0 & 4.5 & 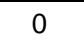 & 42.186 & 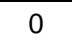 & -20.94 & 4.25 & 205 \\
\hline 3 & 0.49 & 0 & 2.54 & 275 & .96 & 0.47 & 0 & 1.2 & 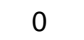 & 3.0348 & 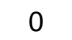 & -20.94 & -2.67 & 205 \\
\hline 4 & 2.5 & 0 & 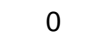 & 375 & 0.92 & 2.3 & 0 & 0 & $v$ & 0 & 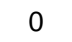 & -20.94 & -5.21 & 305 \\
\hline 5 & 1.09 & 5.07 & 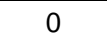 & 500 & 0.8 & 0.872 & 4.4 & 0 & 22.41 & 0 & 0 & -15.87 & -5.21 & 430 \\
\hline 6 & 1.09 & 18.93 & 0 & 500 & 0.8 & 0.872 & 17 & 0 & 312.5 & 0 & 0 & -2.011 & -5.21 & 430 \\
\hline 7 & 1.09 & 29.7 & 0 & 475 & 0.83 & 0.905 & 27 & 0 & 798 & 0 & 0 & 8.75 & -5.21 & 405 \\
\hline 8 & 1.09 & 42.93 & 0 & 475 & 0.83 & 0.905 & 39 & 0 & 1667 & 0 & 0 & 21.98 & -5.21 & 405 \\
\hline 9 & 1.5 & 48 & - & 325 & 0.94 & 1.41 & 68 & 0 & 3249 & 0 & 0 & 27.05 & -5.21 & 255 \\
\hline 10 & 0.22 & 48 & 1.27 & 250 & 0.97 & 0.213 & 10 & 0.3 & 491.7 & 0.3442 & 13 & 27.05 & -3.94 & 180 \\
\hline 11 & 0.22 & 48 & 4.73 & 250 & 0.97 & 0.213 & 10 & 1 & 491.7 & 4.7744 & 48.5 & 27.05 & -0.48 & 180 \\
\hline 12 & 2 & 48 & 6 & 300 & 0.95 & 1.9 & 91 & 11 & 4378 & 68.4 & 547 & 27.05 & 0.78 & 230 \\
\hline 13 & 1.23 & 42.93 & 6.63 & 350 & 0.93 & 1.144 & 49 & 7.6 & 2108 & 50.282 & 326 & 21.98 & 1.418 & 280 \\
\hline 14 & 1.23 & 29.07 & 8.37 & 350 & 0.93 & 1.144 & 33 & 9.6 & 966.7 & 80.138 & 278 & 8.12 & 3.15 & 280 \\
\hline 15 & 1.23 & 18.93 & 9.63 & 375 & 0.92 & 1.132 & 21 & 11 & 405.5 & 104.94 & 206 & -2.01 & 4.41 & 305 \\
\hline 16 & 1.23 & 5.07 & 11.37 & $37^{5}$ & 0.92 & 1.132 & 5.7 & 13 & 29.09 & 146.29 & 65.2 & -15.87 & 6.15 & 305 \\
\hline
\end{tabular}

Table 2. Detailed Resultant (Part :B)

\begin{tabular}{|c|c|c|c|c|c|c|c|c|}
\hline$\alpha \mathbf{T}$ & $\begin{array}{l}\text { E } \alpha \mathrm{T} \\
\text { psi }\end{array}$ & $\begin{array}{c}E \alpha T A \\
\text { lb }\end{array}$ & $\begin{array}{l}\text { E } \alpha \text { TAx } \\
\text { in-lb }\end{array}$ & E $\alpha$ TAy in-lb & C2x & C3y & $\sigma_{\mathrm{xx}} / \mathrm{E}$ & $\begin{array}{l}\sigma_{\mathrm{xx}} \\
\mathrm{psi}\end{array}$ \\
\hline 2.90E-03 & $2.89 \mathrm{E}+04$ & 86722.6 & -1816097.5 & 588719.68 & 0.000525 & -0.00239 & $-9.926 \mathrm{E}-4$ & $-9.926 E+3$ \\
\hline $2.58 \mathrm{E}-03$ & $2.60 \mathrm{E}+04$ & 12757.9 & -267169.96 & 54330.182 & 0.000525 & -0.0015 & $2.566 \mathrm{E}-4$ & $2.592 \mathrm{E}+3$ \\
\hline $2.58 \mathrm{E}-03$ & $2.60 \mathrm{E}+04$ & 12757.9 & -267169.96 & -34082.44 & 0.000525 & 0.000942 & $2.815 \mathrm{E}-3$ & $2.844 \mathrm{E}+4$ \\
\hline 3.84E-03 & $3.71 \mathrm{E}+04$ & 92808.4 & -1943542.9 & -483668.1 & 0.000525 & 0.001838 & $2.493 E-3$ & $2.419 \mathrm{E}+4$ \\
\hline 5.42E-03 & $4.55 E+04$ & 49607.2 & -787337.99 & -258526.3 & 0.000398 & 0.001838 & $7.855 \mathrm{E}-4$ & $6.598 \mathrm{E}+3$ \\
\hline 5.42E-03 & $4.55 E+04$ & 49607.2 & -99782.085 & -258526.3 & 5.04E-05 & 0.001838 & $4.221 \mathrm{E}-4$ & $3.545 \mathrm{E}+3$ \\
\hline $5.10 \mathrm{E}-03$ & $4.45 E+04$ & 48475.1 & 424572.64 & -252626.8 & -0.00022 & 0.001838 & $4.712 \mathrm{E}-4$ & $4.099 \mathrm{E}+3$ \\
\hline $5.10 \mathrm{E}-03$ & $4.45 \mathrm{E}+04$ & 5.1 & 10 & 8 & 55 & 38 & $\mathrm{E}-4$ & $9.379 \mathrm{E}+2$ \\
\hline $3.21 \mathrm{E}-03$ & $3.17 \mathrm{E}+04$ & 47568.4 & 1287134 & -247901.4 & -0.00068 & 0.001838 & $1.865 \mathrm{E}-3$ & $1.846 \mathrm{E}+4$ \\
\hline $2.27 \mathrm{E}-03$ & $2.31 E+04$ & 5081.90 & 137509.09 & -20030.16 & -0.00068 & 0.00139 & $2.341 \mathrm{E}-3$ & $2.388 \mathrm{E}+4$ \\
\hline $2.27 \mathrm{E}-03$ & $2.31 E+04$ & 5081.90 & 137509.09 & -2446.765 & -0.00068 & 0.00017 & 1.063E-3 & $1.085 \mathrm{E}+4$ \\
\hline $2.90 \mathrm{E}-03$ & $2.89 E+04$ & 57815.1 & 1564393.2 & 45589.186 & -0.00068 & -0.00028 & $-3.563 E-5$ & $-3.563 E+2$ \\
\hline 3.53E-03 & $3.45 \mathrm{E}+04$ & 42374.6 & 931756.99 & 60109.866 & -0.00055 & -0.0005 & $-7.653 \mathrm{E}-4$ & $-7.500 \mathrm{E}+3$ \\
\hline 3.53E-03 & $3.45 E+04$ & 42374.6 & 344444.6 & 133841.72 & -0.0002 & -0.00111 & $-1.044 \mathrm{E}-3$ & $-1.024 \mathrm{E}+4$ \\
\hline $3.84 \mathrm{E}-03$ & $3.71 \mathrm{E}+04$ & 45661.7 & -91846.035 & 201758.04 & 5.04E-05 & -0.00156 & $-1.559 \mathrm{E}-3$ & $-1.512 \mathrm{E}+4$ \\
\hline 3.84E-03 & $3.71 \mathrm{E}+04$ & 45661.7 & -724717.99 & 281209.5 & 0.000398 & -0.00217 & $-1.838 \mathrm{E}-3$ & $-1.783 \mathrm{E}+4$ \\
\hline
\end{tabular}

Table 3. Detailed Resultant for Shear Flow

\begin{tabular}{|c|c|c|c|c|c|c|c|c|c|c|}
\hline Node & $\mathbf{A}^{*} \mathbf{i n}^{2}$ & $\mathbf{X}$ in & $\mathbf{Y}$ in & $\mathbf{X i A i}^{*}$ & $\mathbf{Q x}^{*}$ & $\mathbf{Y i A i}^{*}$ & $\mathbf{Q y}^{*}$ & $(\mathbf{a T})^{\mathbf{i}}$ & EiAi & EiAi( $\boldsymbol{\alpha T})^{\mathbf{i}}$ \\
\hline & & & & & 0 & & 0 & & & \\
\hline 15 & 1.13 & -2.0 & 4.4 & -2.28 & -2.28 & 5.00 & 5.00 & $-8.00 \mathrm{E}-06$ & $1.19 \mathrm{E}+07$ & -95.11 \\
\hline 16 & 1.13 & -15.9 & 6.2 & -17.96 & -20.24 & 6.97 & 11.97 & $-8.00 \mathrm{E}-06$ & $1.19 \mathrm{E}+07$ & -95.11 \\
\hline 1 & 2.85 & -20.9 & 6.8 & -59.68 & -79.92 & 19.35 & 31.32 & $-6.04 \mathrm{E}-06$ & $2.99 \mathrm{E}+07$ & -180.64 \\
\hline 2 & 0.47 & -20.9 & 4.3 & -9.85 & -89.77 & 2.00 & 33.32 & $-5.38 \mathrm{E}-06$ & $4.94 \mathrm{E}+06$ & -26.57 \\
\hline 3 & 0.47 & -20.9 & -2.7 & -9.85 & -99.62 & -1.26 & 32.06 & $-5.38 \mathrm{E}-06$ & $4.94 \mathrm{E}+06$ & -26.57 \\
\hline 4 & 2.30 & -20.9 & -5.2 & -48.17 & -147.79 & -11.99 & 20.08 & $-8.00 \mathrm{E}-06$ & $2.42 \mathrm{E}+07$ & -193.32 \\
\hline 5 & 0.87 & -15.9 & -5.2 & -13.84 & -161.63 & -4.54 & 15.53 & $-1.13 \mathrm{E}-05$ & $9.16 \mathrm{E}+06$ & -103.33 \\
\hline
\end{tabular}




\begin{tabular}{|c|c|c|c|c|c|c|c|c|c|c|}
\hline Node & $A^{*}$ in $^{2}$ & $X$ in & $Y$ in & $\mathbf{X i A i}{ }^{*}$ & $\mathbf{Q x}^{*}$ & $\mathrm{YiAi}^{*}$ & $Q y^{*}$ & $(\mathrm{aT}) ' \mathrm{i}$ & EiAi & $\operatorname{EiAi}(\alpha T) ' i$ \\
\hline 6 & 0.87 & -2.0 & -5.2 & -1.75 & -163.38 & -4.54 & 10.99 & -1.13E-05 & $9.16 \mathrm{E}+06$ & -103.33 \\
\hline 7 & 0.90 & 8.8 & -5.2 & 7.92 & -155.46 & -4.71 & 6.27 & -1.06E-05 & $9.50 \mathrm{E}+06$ & -100.97 \\
\hline 8 & 0.90 & 22.0 & -5.2 & 19.89 & -135.56 & -4.71 & 1.56 & -1.06E-05 & $9.50 \mathrm{E}+06$ & -100.97 \\
\hline 9 & 1.41 & 27.1 & -5.2 & 38.15 & -97.41 & -7.35 & -5.79 & $-6.69 \mathrm{E}-06$ & $1.48 \mathrm{E}+07$ & -99.09 \\
\hline 10 & 0.21 & 27.1 & -3.9 & 5.77 & -91.64 & -0.84 & -6.63 & $-4.72 \mathrm{E}-06$ & $2.24 \mathrm{E}+06$ & -10.59 \\
\hline 11 & 0.21 & 27.1 & -0.5 & 5.77 & -85.86 & -0.10 & -6.73 & $-4.72 \mathrm{E}-06$ & $2.24 \mathrm{E}+06$ & -10.59 \\
\hline 12 & 1.90 & 27.1 & 0.8 & 51.41 & -34.45 & 1.50 & -5.24 & $-6.04 \mathrm{E}-06$ & $2.00 \mathrm{E}+07$ & -120.43 \\
\hline 13 & 1.14 & 22.0 & 1.4 & 25.15 & -9.30 & 1.62 & -3.61 & $-7.35 E-06$ & $1.20 \mathrm{E}+07$ & -88.27 \\
\hline 14 & 1.14 & 8.1 & 3.2 & 9.30 & 0.00 & 3.61 & 0.00 & $-7.35 E-06$ & $1.20 \mathrm{E}+07$ & -88.27 \\
\hline
\end{tabular}

Table 3. Detailed Resultant for Shear Flow (continued)

\begin{tabular}{|c|c|c|c|c|c|c|c|c|}
\hline Node & $\operatorname{EiAiYi}(\alpha T)^{\prime} i$ & $\operatorname{EiAiXi}(\alpha T)^{\prime} i$ & $A \mathbf{s}^{*}$ & pxtAs* $/ A^{*}$ & $\Sigma \operatorname{EiAi}(\alpha T)^{\prime} i$ & $C 2{ }^{\prime} Q y^{*}$ & $C 3^{\prime} Q x^{*}$ & $q$ \\
\hline & & & 0.00 & 0.00 & 0.00 & 0 & 0 & 0.00 \\
\hline 15 & -420.26 & 191.32 & 1.13 & 91.07 & -95.11 & -0.36 & -7.17 & -11.57 \\
\hline 16 & -585.76 & 1509.59 & 2.26 & 182.14 & -190.23 & -3.18 & -17.17 & -28.44 \\
\hline 1 & -1226.30 & 3782.93 & 5.11 & 411.51 & -370.87 & -12.57 & -44.93 & -16.86 \\
\hline 2 & -113.17 & 556.52 & 5.58 & 449.37 & -397.44 & -14.12 & -47.81 & -10.00 \\
\hline 3 & 70.99 & 556.52 & 6.05 & 487.23 & -424.02 & -15.67 & -46.00 & 1.53 \\
\hline 4 & 1007.48 & 4048.40 & 8.35 & 672.33 & -617.34 & -23.25 & -28.81 & 2.94 \\
\hline 5 & 538.51 & 1640.03 & 9.23 & 742.51 & -720.67 & -25.42 & -22.29 & -25.87 \\
\hline 6 & 538.51 & 207.85 & 10.10 & 812.69 & -824.00 & -25.70 & -15.76 & -52.78 \\
\hline 7 & 526.22 & -884.38 & 11.00 & 885.50 & -924.98 & -24.45 & -9.00 & -72.93 \\
\hline 8 & 526.22 & -2220.27 & 11.91 & 958.31 & -1025.95 & -21.32 & -2.24 & -91.20 \\
\hline 9 & 516.38 & -2681.10 & 13.32 & 1071.79 & -1125.04 & -15.32 & 8.31 & -60.27 \\
\hline 10 & 41.72 & -286.43 & 13.53 & 1088.96 & -1135.62 & -14.41 & 9.51 & -51.56 \\
\hline 11 & 5.10 & -286.43 & 13.74 & 1106.13 & -1146.21 & -13.51 & 9.66 & -43.92 \\
\hline 12 & -94.96 & -3258.63 & 15.64 & 1259.05 & -1266.64 & -5.42 & 7.51 & -5.50 \\
\hline 13 & -125.21 & -1940.85 & 16.79 & 1351.11 & -1354.90 & -1.46 & 5.18 & -0.07 \\
\hline 14 & -278.79 & -717.48 & 17.93 & 1443.17 & -1443.17 & 0.00 & 0.00 & 0.00 \\
\hline
\end{tabular}




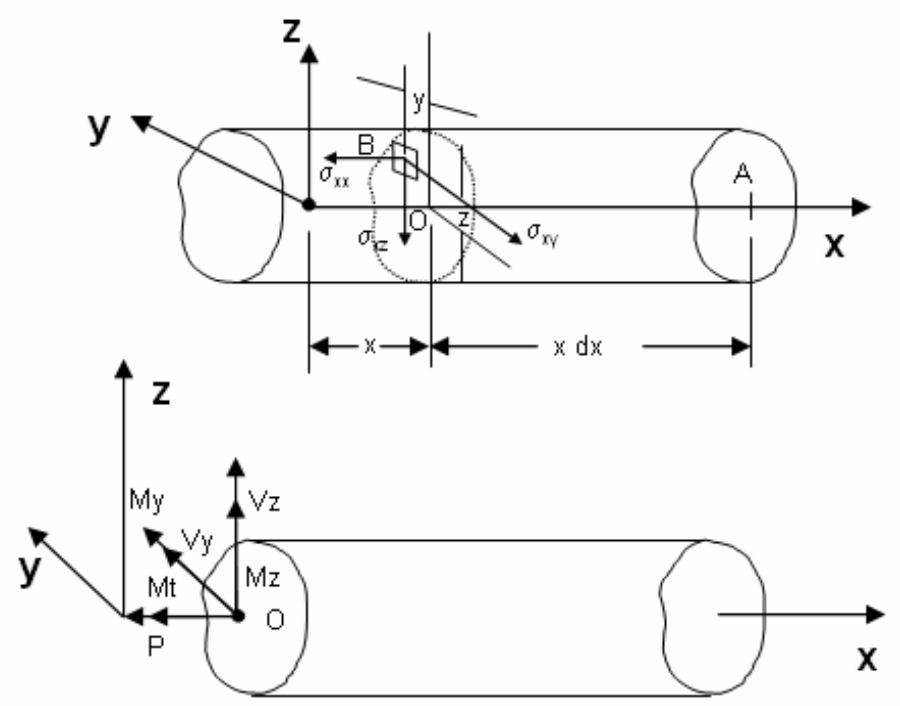

Fig.1. Stresses and Stress resultants on a beam cross section

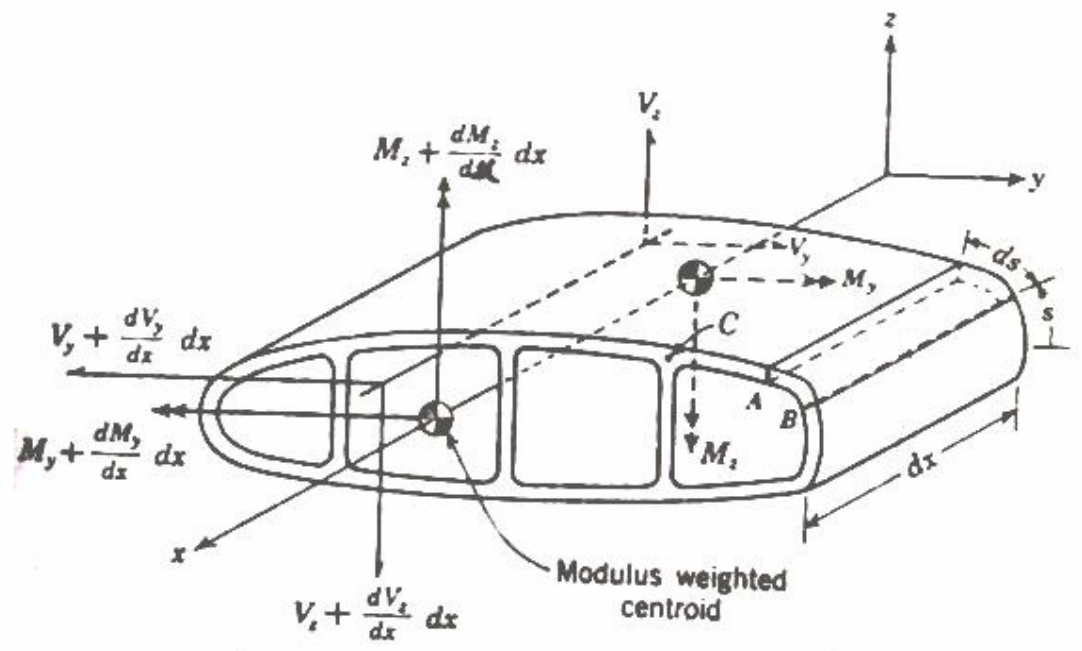

Fig.2. Thin wall section with shear forces

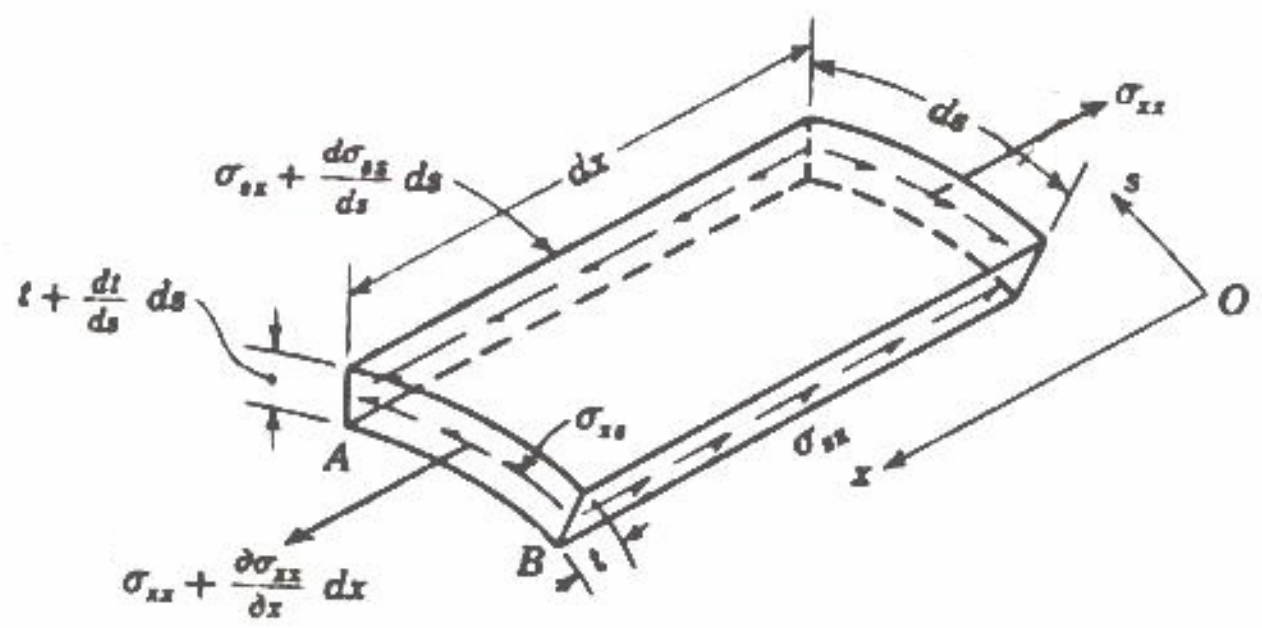

Fig.3. Free body diagram of an element of the wall 

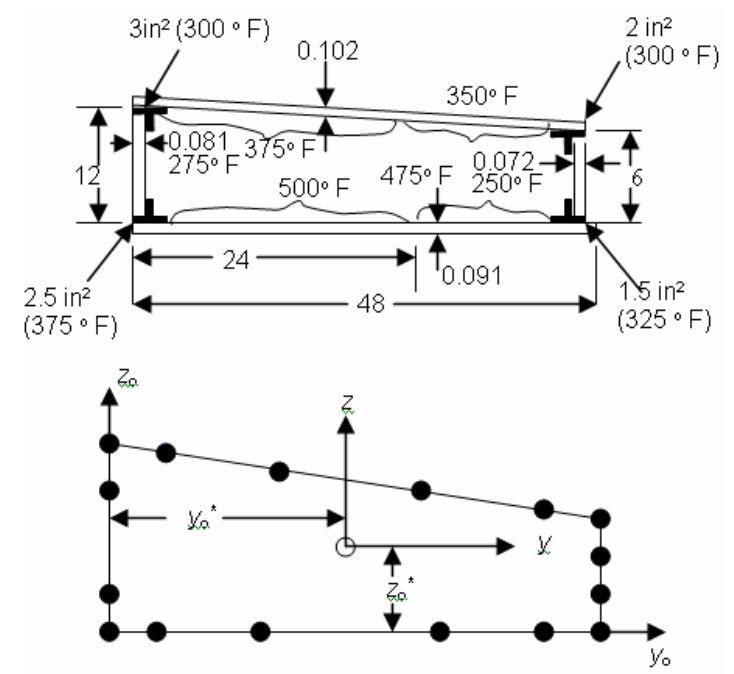

Fig.4. Sectional View of the beam

(actual structure on the top and idealized structure at the bottom)

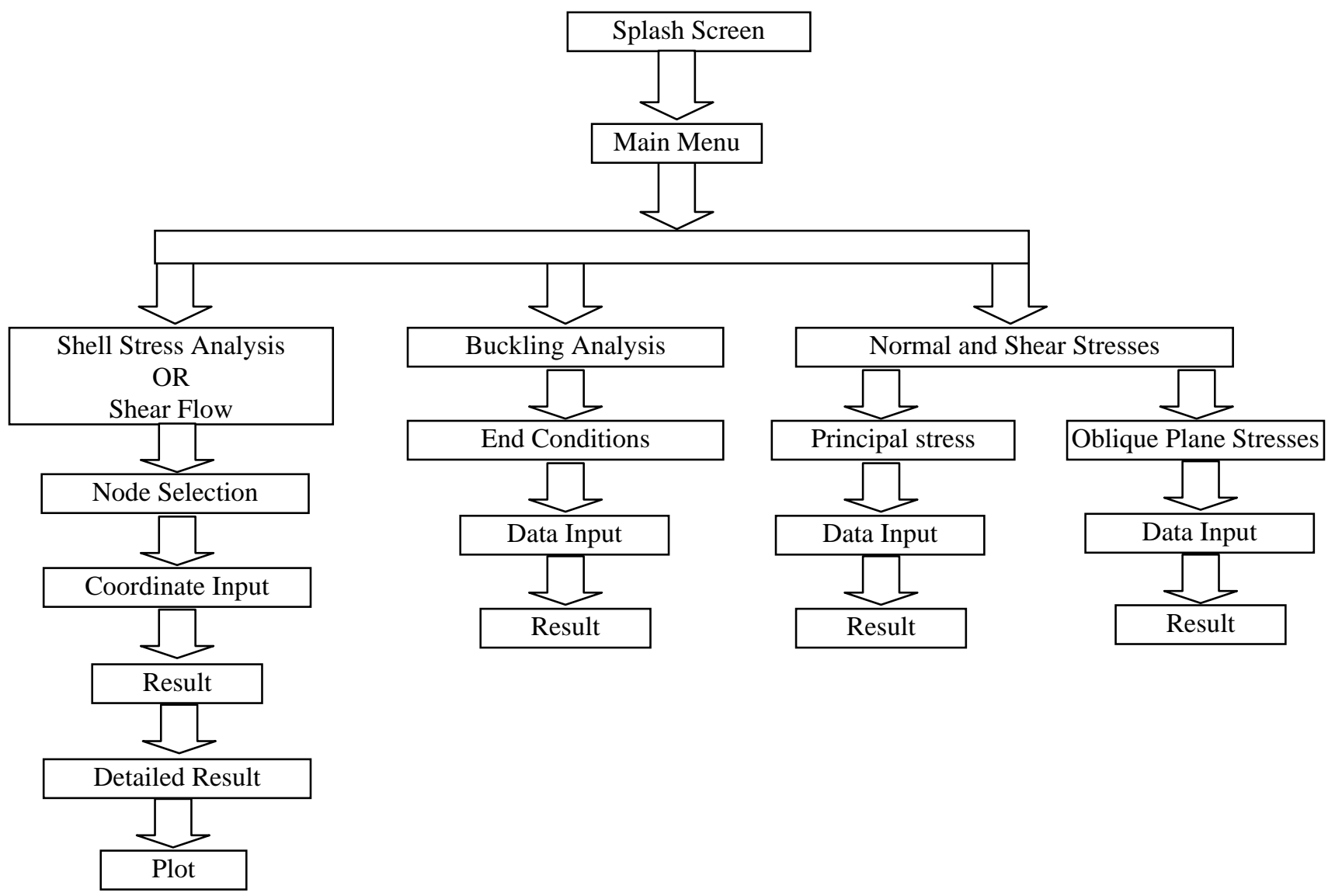

Fig.5. Block Diagram of STATOL ${ }^{\circledR}$ 


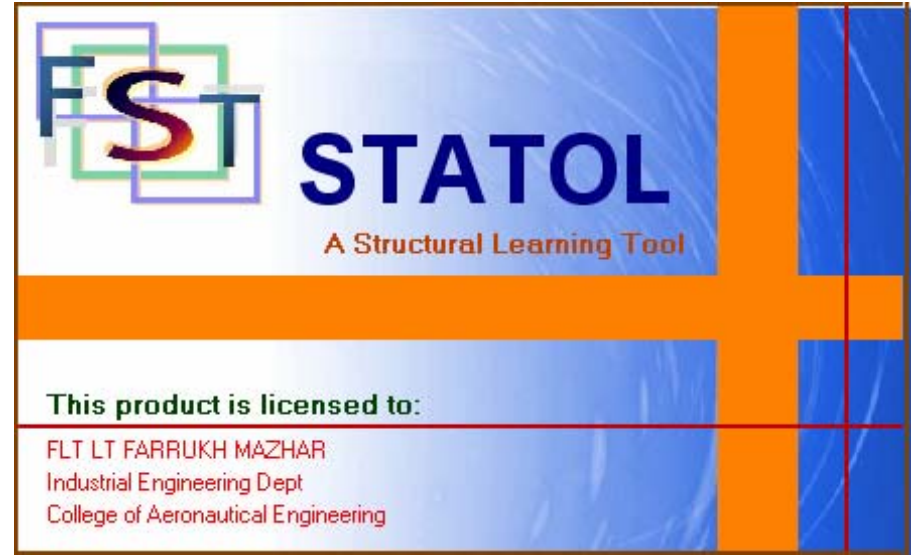

Fig.6. Splash screen of STATOL ${ }^{\circledR}$

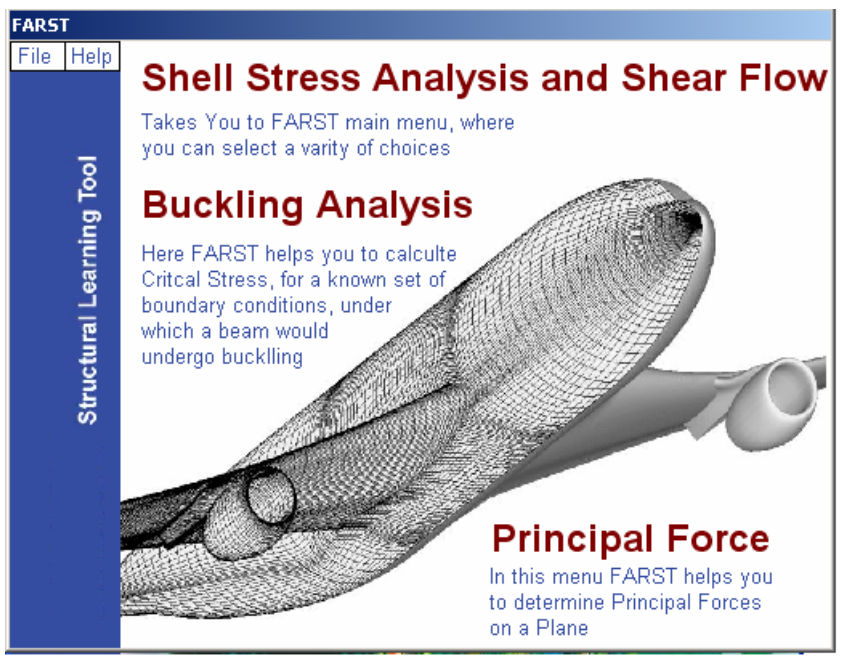

Fig.7. STATOL ${ }^{\circledR}$ Main Menu

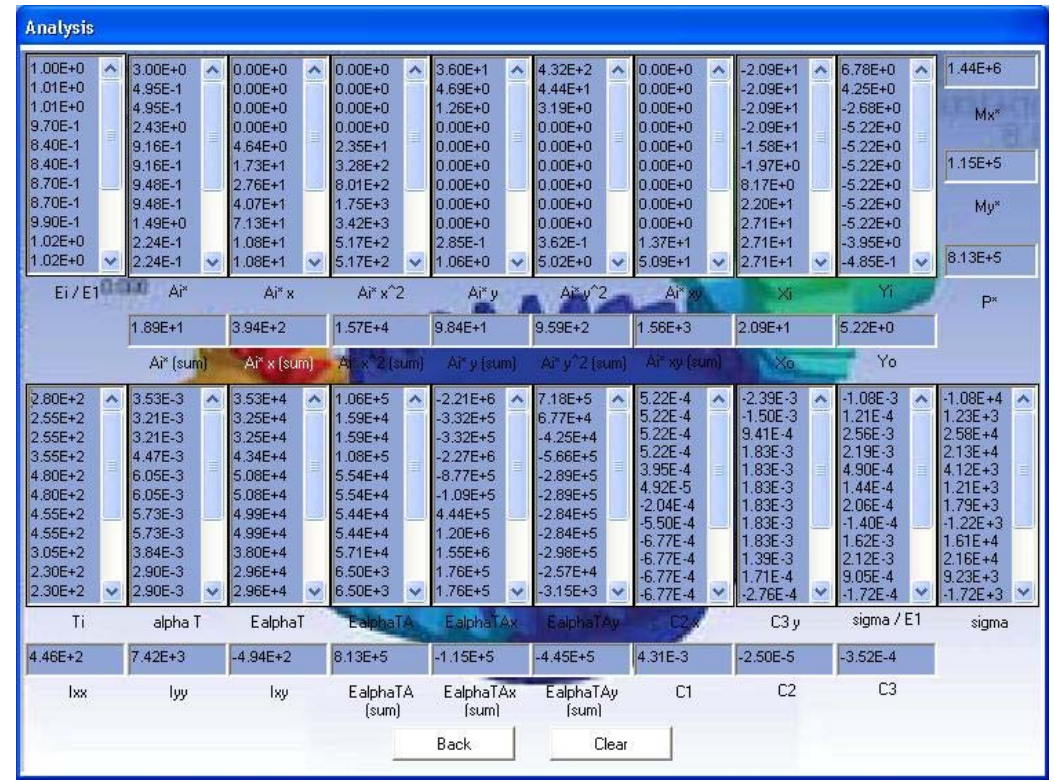

Fig.8. Detailed Structural Analysis 